\title{
TEOLOGÍA NATURAL, TEOLOGÍA REVELADA Y TEOLOGÍA MÍSTICA: REFLEXIONES FILOSÓFICAS A PARTIR DE SANTO TOMÁS DE AQUINO Y SAN JUAN DE LA CRUZ
}

\author{
Natural theology, revealed theology and mystic theology: Philosophical reflections, \\ starting from Saint Thomas Aquinas and Saint John of the Cross
}

\author{
Lucero GonZÁlez SuÁrez
}

\section{Resumen}

¿Qué tipo de discurso en torno a Dios posee preeminencia? ¿Es acaso la teodicea a causa de su base estrictamente racional? ¿Cabe afirmar que el conocimiento por excelencia de lo divino es la teología por tratarse de una reflexión que toma sus principios de la fe? $\mathrm{O}$ ¡es acaso la palabra mística en tanto eco de un encuentro transformador, que hace al hombre Dios por participación? Este artículo constituye un análisis fenomenológico sobre el origen, la condición, los alcances y los límites de tales discursos a partir de la obra de santo Tomás de Aquino y de san Juan de la Cruz. La tesis a demostrar es que, mientras la teología natural y la teología revelada (cuya síntesis magistral es obra del primero) son discursos sobre Dios, la teología mística cristiana (que encuentra su expresión culmen en la obra del poeta místico) es un discurso desde Dios. En última instancia, lo que se pretende es hacer ver que, a causa de su origen inspirado y de su condición sobrenatural, la teología mística es superior tanto a la teología natural como a la teología revelada. De donde se sigue que, cuando el discurso versa sobre el Dios de la fe que viene a la experiencia y no sobre el concepto onto-teológico de Dios, la única palabra que goza de

1 Licenciada, Maestra y Doctora en Filosofía por la Universidad Nacional Autónoma de México. Investigadora Nacional Nivel I del Consejo Nacional de Ciencia y Tecnología. Profesora de la Universidad Intercontinental y de la Universidad La Salle, México. Correo electrónico: lucero.gonzalez@universidad-uic.edu.mx 
autoridad es la del místico porque, en su calidad de testigo de la fe, sus enseñanzas están en plena consonancia con la Revelación.

Palabras clave: Teología; Mística; Teología natural; Teología revelada; Santo Tomás de Aquino; San Juan de la Cruz; Metafísica; Dios.

\section{Abstract}

What kind of discourse around God has preeminence? Is it theodicy, because of its strictly rational basis? Can it be said that the knowledge par excellence of the divine is theology, since it is a reflection that takes its principles from faith? Is it perhaps the mystical word, as an echo of a transforming encounter, which makes man God by participation? This article constitutes a phenomenological analysis of the origin, condition, scope and limits of such discourses, based on the work of Saint Thomas Aquinas and Saint John of the Cross. The thesis to be demonstrated is that, while natural theology and revealed theology (whose masterful synthesis is the work of the former) are discourses on God, Christian mystical theology (which finds its culminating expression in the work of the mystical poet) is a discourse from God. Ultimately, the aim is to show that, because of its inspired origin and its supernatural condition, mystical theology is superior to both natural theology and revealed theology. From which it follows that, when the discourse is about the God of faith that comes to experience and not about the onto-theological concept of God, the only authoritative word is that of the mystic, since, as a witness to the faith, his teachings are fully in line with revelation.

Keywords: Theology; Mysticism; Natural theology; Revealed theology; Saint Thomas Aquinas; Saint John of the Cross; Metaphysics; God.

\section{Introducción}

La palabra "teología" es de origen precristiano. Los términos que la integran "logos en nominativo y Theou en genitivo, significan palabra, razón, discurso sobre Dios, hacia Dios, ante Dios, desde Dios o de Dios" (González de Cardenal, 2006, p. 251). El autor citado parece considerar que tales expresiones son equivalentes. A diferencia de él, considero que, en cada caso, la proposición elegida designa una interpretación peculiar de aquello que nombra la palabra "Dios", derivada de una forma de acceso a su presencia salvadora.

Hablar sobre Dios es una expresión a través de la cual se anuncia un proyecto: hacer de Dios el correlato de una representación. Así entendida la teología tiene por tarea reducir el acontecer de lo divino a los límites del concepto. Tal es el modo de acceso a Dios propio de lo que Heidegger llama “onto-teología”.

Solo se puede hablar hacia Dios y convertirlo en destinatario del discurso cuando se conoce el lugar donde mora su presencia escondida. Hablar hacia Dios solo es posible cuando se ha traspasado el umbral de lo sagrado, es decir, cuando se participa de la experiencia religiosa en sentido auténtico. 
Únicamente habla ante Dios quien sabe orar. La oración es la forma más sublime del decir religioso. La oración es la respuesta balbuciente del hombre ante la manifestación elusiva del Misterio de Dios. Quien ora lo hace animado por el anhelo de estrechar el vínculo entre Aquel que se muestra veladamente para atraerlo hacia sí. La actitud orante nace de la renuncia a la pretensión de forzar a Dios para que muestre su rostro. Orar es aguardar la visita del Amado en actitud receptiva. Mas el hecho mismo de estar a la espera es ya una participación en la presencia deseada.

Solo quien ha llegado a la cima de perfección del proceso místico, en el que la contemplación asume un carácter unitivo, puede hablar desde Dios. La contemplación es conocimiento de orden sobrenatural, que no tiene por causa el trabajo de la inteligencia sino la infusión gratuita de la Sabiduría divina. El discurso místico surge desde Dios porque en las palabras del místico es Dios quien se dice a sí mismo.

Por último, la Sagrada Escritura es palabra de Dios; es hieros logos, porque tiene su origen en Dios mismo. El texto sagrado no solo resguarda del olvido la revelación de la esencia divina, sino que confiere sentido a la existencia de quien se deja interpelar por su mensaje.

La pluralidad de significados de la palabra "teología” tiene en común la referencia a Dios. Pero ¿qué tipo de discurso en torno a Dios posee preeminencia en virtud de su carácter esencial? El propósito de este artículo consiste en responder a este interrogante.

Con el fin de llevar a cabo el propósito mencionado, en primer lugar, se hará una breve presentación del origen y los alcances de la teología natural. A continuación, se exhibirá el fundamento y propósito de la teología revelada. Posteriormente, se explicará que la analogia entis es el fundamento metafísico de la teología escolástica tomista. Una vez hecho lo anterior, se mostrará que, en la propuesta de santo Tomás de Aquino, tiene lugar la síntesis de la teología natural y de la teología revelada. Después de lo anterior, se hará una reconstrucción de la crítica de san Juan de la Cruz a la doctrina de la analogía, encaminada a mostrar las deficiencias de la teología escolástica.

La tesis a demostrar es que, mientras la teología natural y la teología revelada, cuya síntesis magistral es obra de santo Tomás de Aquino, son discursos sobre Dios, la teología mística es un discurso desde Dios. La importancia de tal demostración radica en que, a través de ella, se justifica plenamente la afirmación de que, en virtud de su origen sobrenatural, la teología mística es superior a la teología natural y la teología revelada. De donde se sigue que el discurso sobre Dios no puede contraponerse, sino que tiene que subordinarse al discurso desde Dios, cuyo fundamento último es el discurso de Dios, es decir, la Revelación.

\section{Teología natural: origen y alcance}

De acuerdo con Aristóteles, la metafísica es ontología por cuanto su propósito es el estudio de "lo que es, en tanto que algo que es, y qué-es, y los atributos que le pertenecen en tanto que algo que es" (Metafísica, 1026a31-33). Idea que el filósofo reafirma en otro lugar de su obra al decir que "Hay una ciencia que estudia lo que es, en tanto que algo que es, y los atributos que, por sí mismo, le pertenecen" (Metafísica, 1003a19-20). 
La ontología plantea "la pregunta por el ente en cuanto tal y en su conjunto" (Heidegger, 1988, p. 121). El objetivo de la ontología es doble. Su primera tarea es la "comprensión de los seres 'como tales'; la segunda, se refiere a la comprensión de la 'totalidad' de los seres" (Thomson, 2000, p. 30).

Para descubrir aquello que todos los entes tienen en común y los convierte en tales, la ontología se ve forzada a preguntarse por el ente en general, por eso, desemboca en la reflexión teológica, ya que, para ofrecer un logos que fundamente la multiplicidad de los entes, incurre en un doble movimiento: a) distingue al ser del ente y postula al primero como fundamento del segundo; b) deja en el olvido la diferencia entre ser y ente, al concebir al ser como un ente supremo.

Además de ser ontología, la metafísica es etiología porque su propósito es determinar las causas (aitía) y principios (arché) que, por constituir los fundamentos de las diversas entidades, son aquello que, una vez conocido, abre paso a la comprensión del ser de estas últimas. De tal suerte, la metafísica puede definirse como investigación de los principios y las causas de las entidades, dado que

en todos los casos la ciencia se ocupa fundamentalmente de lo primero, es decir, de aquello de que las demás cosas dependen y en virtud de lo cual reciben la denominación (correspondiente). Por tanto, si esto es la entidad, el filósofo deberá hallarse en posesión de los principios y las causas de las entidades.

(Aristóteles, Metafísica, 1003b18-23)

Además de ontología y etiología, la metafísica es teología, siempre que por ello se entienda la investigación filosófica de "la más excelsa de las cosas que son" (Aristóteles, Metafísica, 1064b4-5), es decir, de la substancia divina, puesto que "lo divino se da en esta naturaleza, si es que se da en alguna parte" (Aristóteles, Metafísica, 1026a18-19).

Entre las dimensiones ontológica, etiológica y teológica de la metafísica se da una relación de complementariedad. Ya que el concepto metafísico de Dios hace de éste una entidad (o substancia) separada e inmóvil, a la cual cabe considerar causa de la substancia o entidad móvil, poseedora de un carácter divino, por cuanto se trata de un principio absoluto y trascendente.

Para Aristóteles, la teología es la "parte superior de los órdenes científicos en cuanto discurso sobre los primeros principios, especialmente sobre el primer motor e inteligencia pura, denominado 'Dios"' (Martin, 2002, pp. 230-231). Tal ciencia es el resultado de la investigación filosófica que, en su esfuerzo por dar razón del ente móvil, sostiene que este solo puede encontrar su razón de ser en la existencia de un principio absoluto.

La teología filosófica es "ciencia divina", porque, de acuerdo con el Estagirita, "si es que hay alguna entidad tal, quiero decir, separada e inmóvil, algo que tratamos de demostrar. Y si, entre las cosas que son, existe una naturaleza tal, allí estará también seguramente lo divino, y ella será también principio primero y supremo" (Metafísica, 1064a35-1064b). La teología es la ciencia teorética más excelsa, cuya misión es indagar la existencia de la entidad separada e inmóvil, a la que cabe caracterizar como "divina" en razón de sus atributos.

En la filosofía aristotélica, el sufijo "logía" del término "teología” designa "un conjunto de relaciones de fundamentación en las que los objetos de las ciencias se representan, o lo que es lo mismo, se comprenden 
desde la perspectiva del fundamento" (Heidegger, 1988, p. 129). El propósito de la teología filosófica o natural es postular a la substancia o entidad suprema como fundamento del ente natural, finito y contingente.

La investigación descrita recibe el título de "teología natural” por cuanto es la sección de la metafísica que tiene por propósito la reflexión sobre el ente supremo y, en tal sentido, divino. En tanto culminación de la metafísica, la teología (natural) griega es ciencia de Dios. Obviamente, en este contexto, la palabra "Dios" hace alusión al ente por excelencia, no al Dios personal del cristianismo.

\section{Teología revelada: fundamento y propósito}

El sujeto de la teología, entendida en sentido amplio, es Dios. No obstante, cabe distinguir entre dos tipos de teología. De acuerdo con santo Tomás de Aquino, la teología natural o filosófica, también llamada filosofía divina o ciencia divina, estudia a Dios desde la luz natural de la razón. Por otro lado, se encuentra "la teología como parte integrante de la sacra doctrina, cuyo conocimiento proviene de la luz divina de la revelación" (Felipe, 2018, p. 141). Esta última es una ciencia positiva que reflexiona sobre Dios, y toma como punto de partida la interpretación de la Sagrada Escritura.

El argumento que santo Tomás de Aquino propone para justificar la existencia de un doble tratamiento teológico de Dios es que

nada prohíbe que sobre las mismas cosas traten (i) las disciplinas filosóficas según que son cognoscibles por la luz natural de la razón, y (ii) otra ciencia, según que se conoce por la luz de la divina revelación. De ahí que la teología, que pertenece a la sagrada doctrina, difiere según el género de aquella otra teología que se coloca como parte de la filosofía. (Suma Teológica I, q. 1, a. 1, ad. 2)

La teología natural o filosófica "procede con fundamentación en el esse creatural, la sagrada doctrina lo hace con fundamentación en la palabra bíblica" (Felipe, 2018, p. 138). El primer tipo de investigación parte del conocimiento del ente contingente y busca demostrar que su fundamento es el Ipsum Esse Subsistens, en el cual coinciden esentia y esse.

La teología revelada o sagrada doctrina tiene su fundamento en la autorrevelación de Dios. Su objetivo es la reflexión "sobre Dios en la medida en que él se ha manifestado en la historia de Israel y en la persona de Jesucristo" (González de Cardenal, 2006, p. 264).

Respecto de la Sagrada Escritura, la teología revelada es un discurso de segundo orden. Por tanto,

no habla directamente de Dios en general, desde sus propias convicciones o deseos, sino a partir de la revelación que aquel hace de sí mismo, tal como fue recogida por los testigos oculares de los momentos fundacionales, fue trasmitida en tradición viviente y quedó sedimentada en los escritos que llamamos Nuevo Testamento. (González de Cardenal, 2006, p. 264) 
La teología revelada tiene por condiciones de posibilidad "la capacidad y apertura del hombre al Absoluto (homo capax Dei) y la revelación de Dios (Deus capax hominis), que se le propone al hombre como su fin supremo, bien máximo y tarea última, es decir como su salvación" (González de Cardenal, 2006, p. 258). La teología revelada tiene "su positividad propia [...] en la fe en el Dios crucificado" (Capelle-Dumont, 2012, p. 40).

La teología revelada tiene por centro la interpretación de la Sagrada Escritura, entendida como "lenguaje primario por excelencia” (Martin, 2002, p. 230). El discurso hacia Dios de la teología revelada encuentra su razón de ser en la interpretación del discurso de Dios. El "estudio de la Escritura debe ser como el alma de la teología [revelada] y de todo el ministerio de la palabra” (Dei Verbum, 24).

La teología revelada tiene un doble propósito. El primero de ellos consiste en hacer comprensible el misterio de Cristo crucificado, hasta donde lo permiten la finitud y limitación del hombre. Esta misión está íntimamente relacionada con la ontología, puesto que todo desvelamiento de un ente presupone la experiencia del sentido del ser en su donación histórica. A la interpretación de Cristo subyace siempre una interpretación histórico-cultural específica del sentido del ser, que opera como el horizonte de comprensión del acontecimiento de la divinidad de Cristo y de la divinidad en Cristo.

El segundo propósito de la teología revelada es dilucidar el sentido de la fe, entendida como apropiación gratuita de los contenidos de la Revelación. Su cometido es dilucidar aquello que constituye al cristianismo en modalidad de la vida fáctica, lo cual exige poner de manifiesto que participar en el acontecimiento de la cruz significa estar "situado ante Dios, y la existencia afectada por dicha revelación" (Heidegger, 2001a, p. 55).

\section{La analogia entis como fundamento metafísico de la teología escolástica tomista}

Las cosas "son": se trata de una evidencia del sentido común que no requiere ni puede ser demostrada. El solo intento de llevar a cabo esta demostración supondría algo absurdo: que la lógica está por encima de la metafísica. Para todo hombre sano e inteligente, resulta evidente tanto su "estar alli", en medio del mundo, como el hecho de que su modo de hacerse presentes posee ciertos rasgos distintivos.

Por el solo hecho de existir en un mundo histórico-cultural específico, en cada caso, nos encontramos ya participando de una cierta comprensión, aun cuando esta sea difusa y vulgar, de aquello que nos sale al encuentro en la experiencia. Las cosas se manifiestan y lo propio de la inteligencia es la apertura a dicha manifestación.

De acuerdo con Aristóteles,

La expresión "algo que es" se dice en muchos sentidos, pero en relación con una sola cosa y a una sola naturaleza y no por mera homonimia, sino que al igual que "sano" se dice en todos los casos en relación con la salud [...] así también "algo que es" se dice en muchos sentidos, pero en todos los casos en relación con un único principio: de unas cosas <se dice que son> por se[r] entidades, de otras por ser afecciones de 
la entidad, de otras por ser un proceso hacia la entidad, o bien corrupciones o privaciones o cualidades o agentes productivos o agentes generadores ya de la entidad ya de aquellas cosas que se dicen en relación con la entidad, o bien por ser negaciones ya de alguna cosa[s] ya de la entidad (Metafísica, 1003a33-1003b9)

Porque la mostración de "lo que es" no se reduce a un solo sentido, la expresión de "lo que es" admite diversos significados. Aquello que unifica tal diversidad de sentidos es la referencia al ser por excelencia: la entidad.

La noción de entidad o substancia no es unívoca: no se dice del mismo modo para todo "lo que es". Pero tampoco es equívoca, en el sentido de que signifique algo radicalmente distinto en cada caso. Es análoga, por cuanto tiene un significado que en parte es igual y en parte es diferente. La analogía es algo intermedio entre la univocidad y la equivocidad.

Toda analogía expresa una relación que se constituye por tres aspectos. El primero es la pluralidad, puesto que "ser análogo a" es una relación comparativa. El segundo es la semejanza, que se relaciona con la univocidad. El tercero es la desemejanza, que origina la equivocidad. En toda analogía, hay un analogado principal, con el cual tienen relación los diversos matices de un significado común, aplicado a entidades que también son diferentes.

La analogía desempeña un papel importante en el conocimiento de aquello a lo que no se tiene acceso directo, ya que "no es preciso buscar una definición de todo, sino que, a veces, basta captar la analogía en su conjunto" (Aristóteles, Metafísica, 1048a). En la Metafísica, existen referencias tanto a la analogía de atribución como a la analogía de proporcionalidad, como recursos para el conocimiento de aquello que escapa a la experiencia. Empero, es obra exclusiva de santo Tomás de Aquino haber aplicado la analogía a la reflexión teológica.

Es solamente en la filosofía medieval donde este uso del término [analogía] llegará a imponerse, y donde el ejemplo que Aristóteles aducía para explicar analógicamente la predicación del Ente -me refiero al de los múltiples sentidos del término "sano"- pasará a ser el prototipo de la llamada "analogía de atribución", mientras que la otra analogía -la única que Aristóteles conoció por este nombre- encontrará un descendiente directo en la analogía de proporcionalidad. (Salas, 2003, p. 156)

El supuesto básico del que partió la filosofía tomista fue que las diversas entidades poseen una relación intrínseca con Dios, por cuanto Éste es causa de la existencia de aquellas. Es decir, ya que tanto la existencia como la esencia de las criaturas son participación de la existencia y esencia de Dios.

Las tres doctrinas fundamentales de la metafísica tomista, que justifican el empleo de la analogía como recurso lógico-semántico para hablar de Dios son:

Primero, el hecho de que existe una distinción entre el ser que es esencialmente existente, bueno y sabio y el ser existente, bueno y sabio por participación. Todo aquello que Dios es, lo es esencialmente [...] Él es la existencia misma, la bondad misma, la sabiduría misma. Las creaturas existen, son buenas y sabias solo por participación en la existencia, bondad y sabiduría de Dios [...] Lo que es esencialmente existente o bueno es la causa de lo que tiene existencia o bondad por participación. En segundo lugar, se encuentra la doctrina general de la causalidad según la cual cada agente produce algo parecido a sí mismo. 
La causalidad y la similitud del agente no pueden separarse. En tercer lugar, está la creencia del Aquinate de que tenemos derecho a afirmar que Dios existe, es bueno, sabio, etc., aunque no podamos conocer su esencia. (Ashworth, 1999, p. 12)

El Aquinate sostiene que a través del conocimiento de las creaturas es posible acceder al conocimiento de Dios como causa; puesto que el efecto tiene cierta semejanza con la causa, las criaturas participan de las perfecciones divinas. De tal suerte, en virtud de la analogia entis, la teología natural está en condiciones de conocer a Dios (como causa) con base en el conocimiento de las criaturas.

A fin de evitar una interpretación errónea de la doctrina tomista de la analogía, es necesario advertir lo siguiente:

Al comparar el uso del término "ser" con "sano" Aristóteles deja en claro que él ve cierta correspondencia entre estos dos casos de analogía. Diferentes cosas que son llamadas "saludables" tienen cierta relación con la salud [...] Algo similar aplica a "ser". Sin embargo, santo Tomás señala que en ambos casos esta relación no es la misma: la sustancia es el sujeto de estos accidentes, cuáles son sus determinaciones: la substancia es el sujeto de los accidentes, los cuales son sus determinaciones. Existe una relación intrínseca y se encuentra algo de ser en los accidentes, mientras que este no es el caso en la relación de alimentos saludables con la salud del cuerpo. Este punto es de gran importancia cuando determinamos la relación de las cosas creadas con Dios: las cosas creadas tienen cierta semejanza con Dios, sobre la base de lo cual son posibles declaraciones análogas sobre ambos. Lo que le pertenece a Dios como idéntico a su esencia, es poseído por las cosas creadas a través de la participación. (Elders, 1993, p. 46)

Las diversas perfecciones que las criaturas poseen pueden atribuirse también a Dios. No obstante,

hay perfecciones que no son sin más compatibles con su esencia (por ejemplo, las que tienen que ver con la materia, como la magnitud, la dureza, etc.); y si la analogía de atribución significa que un predicado -en este caso, una perfección- es atribuido a Dios de manera "más eminente" que a la criatura, resultaría que algunas perfecciones - como el ser mineral y otras- tendrían que ser atribuidas a Dios de manera eminente porque Él las ha creado, y esa atribución es absurda. (Beuchot, 1993, pp. 41-42)

En la Edad Media, filósofos como Duns Scoto afirmaron que el ser se predica unívocamente de Dios y de las criaturas. Para lograr la aceptación de la doctrina de la analogía, santo Tomás de Aquino estaba obligado a refutar esa idea. Por ello, al preguntarse si los nombres dados a Dios y a las criaturas se atribuyen a ambos unívocamente, recoge la objeción según la cual parece que hay algo que se dice unívocamente de Dios y de las criaturas (santo Tomás de Aquino, Suma Teológica I, q. 13, a. 5). En respuesta a esta objeción, el Aquinate argumenta que es imposible que algo se pueda decir unívocamente de Dios y de las criaturas, ya que todo efecto no proporcionado a la capacidad causal del agente recibe la semejanza del agente, pero no en la misma proporción sino deficientemente (santo Tomás de Aquino, Suma Teológica I, q. 13, a. 5).

La tesis central de la metafísica tomista es que el ser no se dice en sentido unívoco cuando se atribuye a Dios y a las criaturas. No obstante, la afirmación de que los seres creados "son" y Dios "es" tampoco es equívoca. Tanto en un caso como en el otro la predicación tiene lugar conforme a la analogía de proporcionalidad. Lo anterior permite que se "pueda hablar de Dios, tomando como punto de apoyo el lenguaje sobre las criaturas, sin que se lo identifique con ellas, y sin que la diversidad de significaciones 
haga incontrolable lógicamente o equívocos esos términos en el proceso de razonamiento" (Beuchot, 1993, p. 44).

La gran aportación de santo Tomás de Aquino a la teología consiste en mostrar que, a partir de lo más conocido en el orden natural (el ser y las perfecciones de las criaturas), es posible arribar al conocimiento de lo menos conocido (Dios como causa). La analogia entis posibilita conocer a Dios como causa a partir de la creación, toda vez que demuestra, por un lado, que el efecto es más evidente que la causa, y por otro que a través del efecto es posible llegar al conocimiento de la causa (santo Tomás de Aquino, Suma Teológica I, q. 2, a. 2).

El ser predicado con analogía proporcional propia "expresa" la comunión en la realidad de todas las cosas desde lo más íntimo de cada una de ellas: su ser, con una relación proporcionada entre lo que cada cosa esencialmente es y su ser, respecto de las demás; ahí se expresa la gradación de los singulares y desde ahí "expresa" a Dios como la realidad por excelencia y nos permite hablar de él desde la proporción desproporcionada, con todos nuestros límites, con toda humildad, pero hablar y subrayar la imagen que en toda realidad hay de Dios. (Antúnez, 2006, p. 29)

La teología que santo Tomás de Aquino inaugura ofrece un conocimiento indirecto de Dios. Tal es su alcance y su límite. El Dios cuyo conocimiento justifica la doctrina de la analogía coincide con lo que Heidegger denomina el "ente fundamentador". Tal identificación resulta problemática, porque, por poco que se repare en ella, surge la pregunta: ¿el dios-fundamento de la metafísica se identifica plenamente con el Dios de la Revelación? En principio, la teología escolástica surge para conocer al Dios de la fe. Sin embargo, por cuanto piensa a Dios desde las categorías de la metafísica griega clásica, sin proponérselo ni desearlo, provoca su desdivinización.

\section{Síntesis de la teología natural y revelada en la escolástica tomista}

Del choque de dos cosmovisiones únicas e irreductibles (la grecorromana y la cristiana), en el siglo II, nace la filosofía medieval. Esta reflexión, que gira en torno a la cuestión de Dios, tiene por principal cometido justificar racionalmente los contenidos de la fe, mediante la utilización de los conceptos fundamentales de la metafísica grecorromana.

¿Cuál es el problema que se deriva de la solidaridad entre teología (tanto natural como revelada) y metafísica, que comienza en la Edad Media y continúa hasta nuestros días? La asimilación "de la filosofía por parte del cristianismo incluye una deformación de este que en definitiva nunca terminará de resolverse" (Carrasco, 2004, pp. 35-36). Para comprender el carácter problemático de dicha asimilación, es imprescindible considerar que, si la diferencia entre la cosmovisión judía y cristiana es notable, la diferencia entre las visiones del mundo cristiana y griega es radical.

Aun cuando la novedad del cristianismo ha quedado oculta por el paso del tiempo, para comprender el impacto que produjo la predicación de la cruz entre quienes se habían formado en la cultura grecorromana, conviene recordar las palabras de san Pablo: "Los judíos exigen milagros y los griegos buscan sabiduría; nosotros, en cambio, predicamos un Cristo crucificado, escándalo para los judíos y necedad para los 
gentiles" (1 Co 1, 22-23). Para la cosmovisión judía, la finalidad de la existencia consiste en estar atento a la Revelación de Dios, quien se comunica con el pueblo elegido a través de los profetas. Por su parte, los filósofos griegos comparten la intuición fundamental de que el ser es fenómeno y se empeñan en indagar el principio y las causas últimas de todo lo que existe, por medio de la investigación racional. A diferencia de ambos, se dicen cristianos quienes han sido interpelados por el Dios vivo y verdadero que se esencia como amor-ágape: Cristo crucificado.

Las aportaciones de la historia de las religiones y de la teología de las religiones, exhiben de forma contundente que Jerusalén no es Atenas. Los filósofos griegos anhelaban la verdad, animados por el impulso erótico de su posesión. Los conversos al cristianismo, que nacieron en la fe judía y entraron en contacto con la cultura grecorromana, solo estuvieron en condiciones de autodenominarse "filósofos" luego de haber modificado de forma significativa el sentido original del término.

Fe y filosofía, tal como esta se comprende desde sus orígenes griegos, son posibilidades existenciales irreductibles y opuestas. La filosofía es, por esencia, pregunta. De acuerdo con Heidegger, "La situación fundamental del preguntar es el sentido del auténtico filosofar" (Kovacs, 1990, p. 11). La fe es afirmación. El hombre de fe no puede preguntar filosóficamente sin dejar de ser creyente; a causa "de su fe y de la seguridad que recibe de ella, no puede atravesar el preguntar 'auténtico' de la pregunta por el ser" (CapelleDumont, 2012, p. 46).

La creencia en un Dios creador hace vana la investigación filosófica que nace de la pregunta por excelencia: ¿por qué hay algo más bien que nada? Entre filosofía y teología existe una relación no esencial.

con el cristianismo, se ha respondido definitivamente a la pregunta acerca de qué es el ente y eliminado así la pregunta misma, y todo esto desde un lugar que es esencialmente superior al opinar y al errar contingentes del hombre. La revelación bíblica, que según ella misma lo indica se apoya en la inspiración divina, enseña que el ente ha sido creado por el Dios creador personal y es conservado y dirigido por él. Gracias a la verdad revelada, proclamada como absolutamente vinculante por la doctrina de la Iglesia, aquella pregunta -qué es el ente- se ha vuelto superflua. (Heidegger, 2000, p. 111)

Para quien la Biblia es la revelación de toda verdad, la pregunta fundamental de la filosofía es superflua. Tal hombre no puede preguntarse ¿por qué el ser y no la nada? Cuando mucho, puede hacer como si se preguntara. Existe "una contradicción existencial (si no es que lógica) entre el cuestionamiento filosófico y la fe religiosa. El creyente no tiene la pasión, o la honestidad, para entrar en el abismo de la cuestionabilidad del ser" (Caputo, 2006, p. 279). En tanto posibilidad existencial, la fe se opone radicalmente a la filosofía.

Cuando se toma como paradigma único la filosofía griega, resulta casi imposible argumentar que la filosofía medieval es filosofía. Los filósofos cristianos se encuentran, por principio, instalados en la fe. Su objetivo principal no es acceder a la comprensión metafísica del ente en general ni del ente divino, sino comprender racionalmente su fe y justificar la verdad de esta ante los no creyentes. Para confirmar esto, basta citar las palabras de san Anselmo de Canterbury:

No intento, Señor, penetrar tu profundidad, porque de ninguna manera puedo comparar con ella mi inteligencia; pero deseo comprender tu verdad, aunque sea imperfectamente, esa verdad que mi corazón 
cree y ama. Porque no busco comprender para creer, sino que creo para llegar a comprender. Creo, en efecto, porque, si no creyere, no llegaría a comprender. (Proslogion, cap. I)

La filosofía griega constituye un preguntar radical, libre de supuestos. La filosofía medieval cristiana es un desarrollo intelectual subordinado a la Revelación. La transformación cristiana de la noción griega de filosofía es tan profunda que no ha faltado quien ponga en entredicho la legitimidad de la aplicación del término para ambas manifestaciones culturales.

Para quien tiene clara la distancia que separa a la filosofía griega antigua de la filosofía cristiana medieval, se impone la pregunta: jen qué punto se da el cruce de dos formas de pensar que en lo tocante a la raíz existencial de la que proceden son diametralmente opuestas? Responder a tal cuestionamiento exige llevar a cabo una breve reconstrucción de la historia de la metafísica, encaminada a mostrar cómo es que Dios se introduce en la filosofía.

La metafísica griega, en su dimensión teológica, postula la existencia de un ente-fundamento de todos los entes y de sí mismo, que es tal en virtud de su mayor rango y jerarquía. Para la teología cristiana, dicho ente no puede ser otro que Dios. Ahora bien, la identificación del Dios cristiano con el ente supremo de la metafísica griega, presente de algún modo en la mayoría de los pensadores medievales, entraña un proceso de desdivinización. Lo sorprendente es que

este golpe no viene de los insensatos que no creen en Dios, sino de los creyentes y sus teólogos, los cuales hablan del ente más ente de todos los entes sin que se les ocurra pensar en el ser mismo, para comprender de este modo, por poco que se metan en la teología de la fe, que este pensar y este hablar, vistos desde la misma fe, son la blasfemia. (Heidegger, 2001b, pp. 216-217)

La teología filosófica o natural "considera a Dios como ser supremo y al ser bajo la forma del ente, sin hacer justicia a Dios ni al ser" (Gesché, 1984, p. 274). Lo primero, porque suplanta al Dios de la fe por un ídolo conceptual, cuya postulación responde a la exigencia de fundamentación. Lo segundo, porque la reflexión ontológica tradicional se desarrolla tomando como punto de partida el olvido del ser en favor del ente.

El gran problema implicado en la representación de Dios como causa (del ente natural) es que, "cuando todo lo presente se presenta a la luz de la conexión causa-efecto, incluso Dios puede perder, para el representar, toda su sacralidad y altura, lo misterioso de su lejanía” (Heidegger, 1994, p. 28). Reducido a causa eficiente y final del ente, el Dios de la Revelación cristiana queda despojado de su divinidad.

En relación con la "injusticia con el ser" de la cual es responsable la metafísica, en la que ya se ha profundizado, baste recordar lo siguiente. A la metafísica, de suyo, "le falta la distinción básica entre la cuestión acerca de los seres particulares (Seiende) y la cuestión acerca del ser en cuanto tal (Sein); esta describe la naturaleza y jerarquía de los seres, pero olvida la cuestión acerca del sentido del Ser" (Kovacs, 1990, p. 9).

La reconstrucción crítica de la historia de la metafísica le permite mostrar a Heidegger que el olvido del Dios de la fe en favor del concepto onto-teológico de Dios hunde sus raíces en un olvido más originario: 
el del ser en favor del ente. El Dios de la fe solo puede manifestarse en el ámbito de lo sagrado. Pero dicho ámbito "solo llega a manifestarse si previamente [...] el ser mismo se ha abierto en su claro y llega a experimentarse en su verdad" (Heidegger, 2006, p. 70). La experiencia del ser en su historicidad posibilita y determina tanto la apertura de lo sagrado como la comprensión de su esencia. Ya que "solo a partir de la verdad del ser se puede pensar la esencia de lo sagrado" (Heidegger, 2006, p. 70).

Las bases metafísicas de la teología natural de la Edad Media tienen su origen en la "recuperación dogmática de las concepciones griegas fundamentales del ser" (Heidegger, 1998, p. 45), de entre las cuales destaca por su importancia la categoría "ousía”. La metafísica es ousiología porque la universalidad de la filosofía primera radica en que esta se cuestiona por la totalidad de los entes, puesto que "su objeto es, entonces, siempre el ente real y no el ser general, ya que la ousía primera es, en todos los casos, la realidad concreta de cada ente" (Ońate, 2001, p. 150). Al haberse representado al Dios de la fe como substancia eterna, la teología natural incurre en una grave contradicción: caracteriza a la substancia eterna como ser en el tiempo: como una entidad cuya nota distintiva es la existencia en un "presente absoluto".

El segundo gran error de la teología natural cristiana, derivado de la utilización de las categorías metafísicas de la filosofía griega antigua, es la confusión de la inmutabilidad con la fidelidad de Dios. Al respecto, vale la pena recordar las palabras de O. Weber: "la esencia de Dios no es, según la Biblia, su absoluteidad-en-sí, sino la permanencia de la relación con la creatura, relación libremente querida por él, la persistencia de su misericordia y fidelidad que eligen” (Moltmann, 2010, p. 264).

Desde sus orígenes griegos, la metafísica identificó "pensar" y "ver". Toda vez que la metafísica piensa al ser como ser-ante-los-ojos, como presencia constante, y posiciona a Dios "como objeto del "ver" (Sehen)" (Meessen, 2006, pp. 49-50), es incapaz de comprender tanto al Dios de la fe como a la experiencia religiosa en su acontecer histórico, ya que "la fe cristiana no trata [...] de lo Eterno como lo absolutamente Otro que queda fuera del mundo y del tiempo humano, sino que trata más bien de Dios en la historia, de Dios como hombre" (Ratzinger, 2013, p. 46).

Por las razones expuestas, la experiencia cristiana de Dios no puede ser comprendida adecuadamente a partir de la teología natural. Pero ¿qué pasa con la teología revelada? ¿Acaso esta ha discurrido por una senda totalmente distinta? Desde sus inicios medievales, la teología revelada "no se ha edificado solo sobre la fe, sino además sobre una luz natural” (Capelle-Dumont, 2012, p. 74).

A la luz de la caracterización antes expuesta, parecería no haber punto de contacto entre la teología natural y la teología revelada. No obstante, por cuanto la segunda ha tomado de la primera sus conceptos fundamentales, tiene con ella una deuda innegable. La consecuencia inevitable de tal préstamo conceptual ha sido la adopción, explícita o ingenua, declarada o encubierta, de los supuestos metafísicos de la filosofía grecorromana clásica. Lo cual ha provocado que el tipo de teología "que de hecho ha prevalecido a partir del siglo XIII ha sido la [de] dimensión metafísica en la medida en que Aristóteles, heredado por santo Tomás, sitúa la ciencia teológica como la suprema junto a la matemática y a la física" (González de Cardenal, 2006, p. 258).

No es que la teología haya ignorado los riesgos de enfeudamiento. Las protestas paulinas y patrísticas contra las sabidurías de este mundo en favor de la locura de la cruz y las correcciones incesantes del aristotelismo 
propuestas por la gran escolástica dan testimonio suficiente de ello. Pero la orientación general de la teología fue una "patriótica" confianza en los recursos de la razón filosófica, de la que ella hizo su principal auxiliar (philosophia, ancilla theologiae). (Gesché, 1984, p. 274)

La utilización de las categorías metafísicas de la teología natural de raíz grecorromana derivó en la construcción de una teología revelada que olvidó, casi por completo y por demasiado tiempo, la advertencia paulina sobre la imposibilidad de reducir el acontecimiento de la cruz a los límites de la comprensión racional. La teología "no fue capaz de librarse, durante casi dos milenios, de la envoltura helénica de sus conceptos lingüísticos” (Ratzinger, 2013, p. 230).

En la escolástica tomista, la estrecha vinculación de la teología revelada con la teología natural o filosófica se justifica apelando a la relación existente entre fe y razón. De acuerdo con santo Tomás de Aquino,

tanto lo que conocemos naturalmente, como lo que conocemos por fe tiene por origen a Dios, pues él no solo nos infunde la fe sobrenaturalmente, sino que al crear nuestra naturaleza, con-creó la luz natural de la razón por la que a todos se nos hacen evidentes los primeros principios, de los cuales deriva de algún modo todo nuestro conocimiento natural, no puede haber verdadera contradicción entre el saber natural, especialmente la ciencia, y la fe. (Echavarría, 2013, p. 151)

Tanto la fe como la razón tienen su origen en Dios, aunque no del mismo modo: la fe es un hábito sobrenatural infuso, mientras la razón, por la que todo hombre es capaz de comprender los primeros principios, forma parte de su condición creatural. Ahora bien, a pesar de su distinta procedencia, dado que fe y razón tienen a Dios por causa, no cabe esperar que entre ellas se dé contradicción.

De acuerdo con santo Tomás de Aquino, puesto que entre razón y fe no puede haber contradicción, ante cualquier discrepancia, dada la excelencia de la fe, que contrasta con la deficiencia de la razón, debe tomarse por verdadero aquello que se conoce por fe. Ya que, respecto de lo que en sí mismo es más evidente, "nuestro intelecto es como el ojo del murciélago en relación con la luz del día" (Aristóteles, Metafísica, 993b10). Por esta razón, se debe conceder mayor autoridad a la fe que a la razón.

Para comprender lo anterior, es necesario recordar que en el tiempo de santo Tomás de Aquino tuvo lugar una importante disputa entre quienes defendían, como Avicena, que el objeto de la metafísica era lo relativo el ser, ${ }^{2}$ y quienes aseguraban, junto con Averroes, que era lo divino. ${ }^{3}$ En franca oposición a la postura de Averroes, santo Tomás de Aquino rechaza la posibilidad de que la razón natural pueda elevarse

2 Avicena rechaza la identificación de Dios con el ser, bajo el argumento de que "Dios no es un objeto de estudio ( $\left.m a w d \bar{u}^{\prime}\right)$ por cuanto Su existencia y Su esencia no nos son conocidas y, por consiguiente, no pueden ser admitidas de antemano como los objetos de investigación de la filosofía primera: la metafísica -como toda ciencia peripatética-versa siempre sobre un objeto cuya existencia puede ser identificada y desde la cual sus modos son indagados, condición que Dios no puede cumplir en tanto que Él -por su radical simplicidad y unicidad-carece de modos, atributos y género próximo, que constituye, consecuentemente, un límite lógico en la descripción y especulación filosófica” (Figueroa, 2019).

3 De acuerdo con este destacado filósofo, la metafísica "estudia los principios de la sustancia, que son los seres separados, dando a conocer cuál sea el ser de éstos y relacionándolos con su primer principio, que es Dios -sea bendito y ensalzadode quien da a conocer los atributos y actos que le son propios. Explica además, la relación de Él con los demás seres y demuestra que Él es la perfección última y la forma y agente primarios” (Averroes, 1919, p. 12). 
a la comprensión de la sustancia puramente incorpórea. Según el Aquinate, no puede haber una ciencia de orden natural que tenga a la naturaleza divina, en cuanto tal, por objeto de investigación.

Santo Tomás de Aquino sostiene, siguiendo a Avicena, que el objeto de una ciencia lo constituye la naturaleza cuyas causas y atributos se busca conocer. Así, no se ha de pensar que las causas son el sujeto de la teología. De este modo, la metafísica deja de ser ontología y se convierte en teología natural o filosófica, por cuanto, en su investigación del ente, arriba a la consideración de lo divino, entendido como causa primera y universal del primero.

Del planteamiento enunciado, se colige que solo Dios y quienes gozan de la visión sobrenatural de su esencia conocen la naturaleza divina. Únicamente por la Revelación, quien no posee la ciencia de los bienaventurados, está en condiciones de instruirse y creer en lo que Dios ha dicho de sí mismo.

Con el propósito de esclarecer las verdades reveladas, santo Tomás de Aquino se pregunta si la teología revelada o doctrina sagrada es ciencia. Es fácil comprender el origen de tal cuestionamiento: la interpretación de los textos sagrados abre paso a una gran cantidad de problemas especulativos, cuyo correcto planteamiento exige disponer de definiciones rigurosas.

Bajo el entendido de que la razón debe propiciar la fe, santo Tomás de Aquino defiende el derecho de la teología a argumentar a partir de la triple necesidad de confirmar la fe del creyente, elaborar una defensa de la fe en contra de quienes incurren en herejías y promover la fe.

Según santo Tomás de Aquino, toda verdad proviene de Dios. Una vez aceptado lo anterior, cabe sostener que el estudio de la filosofía es digno de alabanza, ya que la verdad a la que acceden los filósofos, en última instancia, tiene su origen en la automanifestación de Dios a través de sus obras.

Respecto de la sagrada doctrina, la filosofía constituye una gran ayuda porque proporciona analogías que ayudan a comprender lo sobrenatural a partir de las cosas que son naturalmente cognoscibles, ayuda a argumentar contra las posiciones contrarias a la fe, ya sea probando que son falsas, ya sea demostrando que no son ciertas por necesidad, ofrece pruebas de los preámbulos de la fe, es decir, aquellas verdades que pueden ser conocidas por la razón, de entre las cuales destaca por su importancia la existencia de Dios.

La doctrina sagrada es una ciencia peculiar, por cuanto toma como punto de partida los artículos de la fe. La teología es ciencia especulativa, que depende de una ciencia superior: "la de Dios y los bienaventurados". Esta última tiene su origen en la participación sobrenatural en la Sabiduría divina por fe, de la cual afirma la Sagrada Escritura que, al hombre justo, "le guio por caminos rectos; le mostró el reino de Dios y le dio el conocimiento de las cosas santas" (Sab 10,10).

Según santo Tomás de Aquino, fe y teología se relacionan en un doble sentido. Por un lado, sin la fe la teología no alcanza sus principios; por otro, al reducir a conceptos las experiencias de los testigos de la fe, la teología hace comprensible, incluso, para el no creyente, el sentido de la Revelación.

Para el Aquinate, el conocimiento de las entidades sensibles depende de las imágenes o fantasmas de estas. Evidentemente, a Dios no se tiene acceso de esa manera. En virtud de su capacidad natural, el hombre solo puede conocer a Dios a través de los fantasmas que provienen de los efectos de su actividad 
creadora. Lo cual justifica la confianza en que la razón puede comprender a Dios por sus efectos, aun cuando esto tenga lugar de manera indirecta y limitada.

La confianza en que a partir del conocimiento natural de la razón el intelecto "es más fácilmente llevado de la mano a las cosas que superan a la razón, que se transmiten en esta ciencia" (santo Tomás de Aquino, Suma Teológica I, q. 1, a. 5, ad 2), es decir, en la sagrada doctrina, se basa en la analogia entis.

Santo Tomás de Aquino argumenta a favor de la aplicación de la analogía (tanto de atribución como de proporcionalidad) al ejercicio de la teología. Pero el ser de Dios no se agota en la creación. Dios, como señaló san Anselmo en el Proslogion, no solo es "Aquello mayor que lo cual nada puede pensarse", ante todo es "aquello mayor que lo cual, nada puede ser pensado".

\section{La crítica de san Juan de la Cruz a la doctrina de la analogía}

Santo Tomás de Aquino sostiene que los nombres dados a Dios y a las criaturas se atribuyen por analogía o proporcionalmente. El hombre y Dios se asemejan en la medida en que la perfección puede predicarse de ambos. Sin embargo, las perfecciones de las criaturas se distinguen de la esencia de estas, mientras en el Creador preexisten unidas en su esencia.

Cuando los nombres que designan perfecciones se atribuyen a Dios, nombran una realidad eminente; cuando se atribuyen a las criaturas, nombran una realidad participada. En el orden del ser, aquello que los nombres refieren corresponde a Dios por principio y a las criaturas de forma derivada. En el orden del conocimiento, puesto que no conocemos la causa sino a través del efecto, los nombres que se atribuyen a Dios y a las criaturas por analogía pertenecen a las criaturas antes que a Dios, puesto que no es posible nombrar a Dios sin tomar como punto de partida los entes finitos. Acerca de la existencia y esencia de Dios, solo conocemos lo que sus obras manifiestan.

Solo si entre Dios y las criaturas hay una cierta semejanza, es posible confiar en que la vía a posteriori conduce al conocimiento del primero. La analogia entis es el fundamento de la doctrina de la analogía como recurso lógico-semántico para el conocimiento racional de Dios, aunque de forma indirecta y desproporcionada, puesto que el ser de Dios es sobrenatural mientras el conocimiento analógico es de orden natural.

Ahora bien, cuando se afirma que el fin último de la existencia es el conocimiento de Dios, ¿qué se quiere dar a entender con la palabra "conocimiento"? De acuerdo con el Evangelio según san Juan, el fin último del hombre es la unión mística con Dios en Cristo, que consiste en conocer y amar a Dios del mismo modo que Él se conoce y se ama en cada una de las personas de la Santísima Trinidad y ama al hombre. Esto pone de manifiesto que el conocimiento que conduce a la salvación, para el cual fue creado el hombre, no es de orden natural (independientemente de si la naturaleza de este es filosófica o teológica), sino sobrenatural.

En su Comentario al Evangelio según san Juan, al interpretar las palabras con las que este inicia, "En el principio era la palabra" (Jn 1, 1), santo Tomás de Aquino explica que, si la Palabra habita en una luz 
inaccesible (1 Tim 6, 16), es porque "no pueden ver los secretos de la divinidad sino quienes tienen en sí la gracia de Dios” (prólogo, proemio 10). Afirmación con la cual el filósofo y teólogo da a entender que el conocimiento sobrenatural de la divinidad pertenece únicamente a quienes "por el afecto y el intelecto, se adhieren a la suma verdad contemplada" (Comentario al Evangelio según San Juan. Tomo I, prólogo, proemio 8).

Al igual que santo Tomás de Aquino, san Juan de la Cruz acepta que las noticias naturales capacitan al hombre tanto para el conocimiento de la existencia y de la esencia de las entidades naturales como para el conocimiento indirecto de Dios como causa de estas.Entre el conocimiento natural del hombre y Dios como causa de la creación (en su calidad de mero principio metafísico) existe la proporción requerida.

De acuerdo con una regla filosófica que san Juan de la Cruz cita en diversos lugares de su obra, "todos los medios han de ser proporcionados al fin, es a saber: que han de tener alguna conveniencia y semejanza con el fin, tal que baste y sea suficiente para que por ellos se pueda conseguir el fin que se pretende" (Subida del Monte Carmelo, libro 2, capítulo 8, párrafo 2). De donde se sigue que, dada la falta de proporción entre los medios (de la teología natural) y el fin último del hombre (que consiste en el conocimiento sobrenatural del ser sobrenatural de Dios), si bien goza de relevancia en el campo de la investigación filosófica, el conocimiento analógico de Dios carece de utilidad para la salvación.

El conocimiento que conduce a la salvación no se refiere a Dios como causa de las substancias naturales, sino a Dios como realidad sobrenatural. El misterio de Dios solo se descubre veladamente para quien participa de la contemplación o teología mística. De donde se sigue que el hombre se ha de "apartar de su inteligencia para llegarse a Dios" (san Juan de la Cruz, Llama de amor viva B, canción 3, párrafo 48), puesto que el ámbito donde acontece la presencia divina no es el conocimiento metafísico sino la fe.

\section{Conclusiones}

En comparación con la Sabiduría de Dios de la que participan los testigos de la fe, la importancia de la teología revelada, y con mayor razón la teología natural, es secundaria. En tanto medio remoto para la unión con Dios, el valor del discurso teológico consiste única y exclusivamente en propiciar una correcta comprensión de la esencia divina. Propósito que, a su vez, exige la utilización de conceptos fundamentales originarios, nacidos de la fe sobrenatural, entendida como virtud teologal, cuyo hábito y acto se originan en la contemplación infusa.

Como explica Heidegger en su magistral reflexión "Fenomenología y teología”, la teología revelada no puede obtener "sus categorías de pensamiento ni sus modos lingüísticos de la filosofía [...] sino a partir de la fe y para servir a la fe" (Solari, 2014, p. 295). Por cuanto no es una mera especulación metafísica, sino que está ordenada al fin último de la salvación, la teología revelada no puede recurrir a la metafísica para extraer de ella las categorías que han de señalar el curso del pensar que la define, ni la modalidad del decir que debe adoptar. Tal restricción obedece al hecho de que "Todo conocimiento teológico fundamenta su legitimidad concreta sobre la propia fe, esto es, nace de ella y a ella retorna” (Heidegger, 2001a, p. 61).

Como los místicos bien saben, la fe sobrenatural, antes que una modalidad de conocimiento, es una forma de vida; es participación del hombre en el misterio de Dios. Idea en la que el concepto de 
participación hace alusión a la experiencia de estar "situado ante Dios, y la existencia afectada por dicha revelación" (Heidegger, 2001a, p. 55).

La fe no apunta hacia sí misma, ya que "no se cree en la propia fe, sino que en sus experiencias de fe y en sus decisiones se cree a otro que es más que la propia fe. La identidad cristiana únicamente puede comprenderse como acto de identificación con Cristo crucificado" (Moltmann, 2010, p. 42). La cruz es el lugar donde se revela plenamente, lo cual no significa que se desvela del todo, la divinidad de Cristo. Por tanto, la teología revelada por excelencia es, como ya lo decía san Pablo, la teología de la cruz.

El Dios de la onto-teología es un concepto que, en un sistema metafísico, hace las veces de principio. El Dios de la fe es Cristo crucificado y resucitado. No hay proporción entre el ser sobrenatural de Dios (que se conoce por fe) y el dios-ídolo de la razón natural. La aparición de la fe tiene por condición previa superar la tentación de hacer a Dios una entidad capaz de ser aprehendida racionalmente.

En atención a la distinción entre el Dios de la fe y el Dios de la metafísica onto-teológica, la pregunta que se impone es esta: ¿qué tipo de relación cabe establecer entre la teología escolástica, en la que la herencia metafísica pesa más que la experiencia de Cristo crucificado, y la teología mística, claramente cristocéntrica, de la cual han dado testimonio personas como san Juan de la Cruz? Antes de ofrecer una respuesta, vale la pena considerar que la relación entre fe y razón es un problema perenne. Su separación hace vana la teología revelada. Su confusión resulta aún peor, por cuanto elimina la distancia entre dos experiencias fundamentales e irreductibles. A saber: pensar y creer.

Según se entienda la relación entre lo natural y lo sobrenatural, se abren dos posibles caminos para el conocimiento de la verdad que Dios es. El primero es la senda por la que discurre la teología escolástica, según la cual, "porque todo lo que es participa del ser y es ente por participación, es necesario que haya algo en la cumbre de todo, que ser 'ser' él mismo por su esencia, esto es, que su esencia es su ser; y esto es Dios, que es causa y muy suficiente, dignísima y perfectísima de todo ser" (santo Tomás de Aquino, Comentario al Evangelio según san Juan. Tomo I, prólogo, proemio). El segundo camino, al que solo cabe entender como un ascenso al monte de perfección espiritual, es la teología mística. La cual tiene como punto de partida el reconocimiento de que "la palabra de la cruz es locura a los que se pierden [...] Porque lo insensato de Dios es más sabio que los hombres, y lo débil de Dios es más fuerte que los hombres” (1 Cor 1: 18, 25).

La teología revelada o "doctrina sagrada se adquiere por el estudio, en cambio, la sabiduría es infusa" (santo Tomás de Aquino, Suma Teológica I, q. 1, a. 6). La teología, tanto natural como revelada, es un conocimiento de orden natural, fruto del esfuerzo intelectual. Para comprender a Dios como causa, no se requiere el auxilio divino y tampoco hace falta tener fe. Por el contrario, la Sabiduría que le es infundida al místico en contemplación es conocimiento sobrenatural de Dios.

Por todo lo anterior, la respuesta a la pregunta inicial acerca de cuál de los discursos en torno a Dios tiene primacía es obvia: solo la teología mística, en tanto experiencia radical de Dios, es origen de un discurso desde Dios. 


\section{Referencias}

Antúnez, J. (2006). La analogía: Perspectivas. En A. Pérez de Laborda (ed.), Jornada sobre la analogía (pp. 15-42). Universidad san Dámaso.

Aristóteles. (1994). Metafísica. Gredos.

Ashworth, E. J. (1999). Medieval theories of analogy. En The Stanford Encyclopedia of Philosophy. https://plato. stanford.edu/entries/analogy-medieval/

Averroes. (1919). Compendio de metafisica. Real Academia de Ciencias Morales y Políticas.

Beuchot, M. (1993). Signo y lenguaje en la filosofia medieval. Universidad Nacional Autónoma de México.

Brook, A. (2010). Heidegger's Notion of Religion: The limits of being-understanding. Forum Philosophicum, 15(1), 45-64. https://doi.org/10.5840/forphil201015117

Capelle-Dumont, P. (2012). Filosofia y teología en el pensamiento de Martin Heidegger. Fondo de Cultura Económica.

Caputo, J. (2006). Heidegger and theology. En C. Guignon (ed.), The Cambridge Companion to Heidegger (pp. 270-288). Cambridge University Press.

Carrasco Pirard, E. (2004). Heidegger y el cristianismo. Revista de Filosofia, 60, 29-56. https://repositorio.uchile. cl/handle/2250/131743

Carrasco Pirard, E. (1969). Constitución dogmática Dei Verbum: Sobre la divina revelación. En Documentos del Vaticano II (pp. 113-133). Biblioteca de Autores Cristianos.

Echavarría, M. F. (2013). La analogía de fe y razón en santo Tomás de Aquino. Espíritu: Cuadernos del Instituto Filosófico de Balmesiana, 62(145), 147-160. https://www.revistaespiritu.org/la-analogia-fe-razon-santo-tomas-aquino/

Elders, L. J. (1993). The Metaphysics of Being of St. Thomas Aquinas in an historical perspective. E. J. Brill.

Felipe Mendoza, J. M. (2018). Tomás de Aquino y la relación entre filosofía y teología: Una interpretación literal de la Suma de Teologia I, Q. 1, Art. 1. Universitas Philosophica, 35(70), 131-149. https://doi.org/10.11144/ javeriana.uph35-70.arft

Figueroa Lackington, B. (2019). Avicena o la ontología de lo común. Reflexiones Marginales, 51. https://2018. reflexionesmarginales.com/avicena-o-la-ontologia-de-lo-comun/

García, S. (2006). "La analogía entre el ser finito y el ser infinito: Analogia entis". En A. Pérez de Laborda (ed.), Jornada sobre la analogia (pp. 131-182). Universidad san Dámaso.

Gesché, A. (1984). “Teología dogmática”. En B. Lauret y F. Refoulé (eds.), Iniciación a la práctica de la teología. Tomo $I$ (pp. 270-292). Cristiandad.

González de Cardenal, O. (2006). "El quehacer de la teología”. Salmanticensis, 53(2), 251-299. https://doi. org/10.36576/summa.29722

Heidegger, M. (1994). La pregunta por la técnica. En Conferencias y artículos (pp. 9-37). Ediciones del Serbal.

Heidegger, M. (1998a). La constitución onto-teológica de la metafísica. En Identidad y diferencia (pp. 99-157). Anthropos.

Heidegger, M. (1998b). Ser y tiempo. Editorial Universitaria.

Heidegger, M. (2000). El nihilismo europeo. En Nietzsche II (pp. 31-206). Destino. 
Heidegger, M. (2001a). Fenomenología y teología (pp. 49-65). En Hitos. Alianza.

Heidegger, M. (2001b). La frase de Nietzsche Dios ha muerto. En Caminos de bosque (pp. 157-198). Alianza.

Heidegger, M. (2006). Carta sobre el humanismo. Alianza.

Kovacs, G. (1990). The question of God in Heidegger's Phenomenology. Northwestern University Press.

Martin, J. P. (2002). Religión y teología. En F. Díez de Velasco y F. García Bazán (coords.), El estudio de la religión (pp. 227-258). Trotta.

Moltmann J. (2010). El Dios crucificado. Sígueme.

Oñate, T. (2001). Para leer la Metafísica de Aristóteles en el siglo XXI. Dykinson.

Ratzinger, J. (2013). Introducción al cristianismo. Sígueme.

Salas, M. (2003). santo Tomás: Analogía y participación. Revista de Filosofía de la Universidad de Costa Rica, 41(104), 153-165.

San Anselmo. (2007). Proslogion. Folio.

San Juan de la Cruz (2003). Obras completas. Monte Carmelo.

Santo Tomás de Aquino. (2001). Suma de teología I. Parte I. Biblioteca de Autores Cristianos.

Solari, E. (2014). El problema de Dios según Heidegger y otros ensayos de fenomenología, religión y cristianismo. Universitarias de Valparaíso.

Thomson, I. (2000). Ontotheology? Understanding Heidegger's destruktion of metaphysics. International Journal of Philosophical Studies, 8(3), 297-327. https://doi.org/10.1080/096725500750039291 